\title{
Predictors of survival in adults undergoing extracorporeal membrane oxygenation with severe infections
}

\author{
Aristine Cheng, MD, ${ }^{\mathrm{a}, \mathrm{b}}$ Hsin-Yun Sun, MD, ${ }^{\mathrm{b}}$ Mao-Song Tsai, MD, ${ }^{\mathrm{c}}$ Wen-Je Ko, MD, ${ }^{\mathrm{d}} \mathrm{Pi}-\mathrm{Ru}$ Tsai, BSc, \\ $\mathrm{Fu}-\mathrm{Ch}$ ang $\mathrm{Hu}, \mathrm{ScD},{ }^{\mathrm{e}}$ Yee-Chun Chen, $\mathrm{MD}, \mathrm{PhD},{ }^{\mathrm{b}}$ and Shan-Chwen Chang, $\mathrm{MD}, \mathrm{PhD}^{\mathrm{b}}$
}

\section{ABSTRACT}

Background: To identify novel factors associated with the survival of septic adults receiving extracorporeal membrane oxygenation (ECMO) to improve patient selection and outcomes.

Methods: Cases were identified from our ECMO registry from 2001 to 2011 if they were $\geq 16$ years and received ECMO for life-threatening sepsis.

Results: A total of 151 adults with a median (25th-75th percentile) age of 51 (37$63)$ years were analyzed. Pneumonia (50\%), myocarditis $(20 \%)$, and primary bloodstream infections $(15 \%)$ were the main types of infection, caused by predominantly nonfermentative Gram-negative bacteria (NFGNB) (26\%), Enterobacteriaceae (24\%), and Gram-positive cocci (21\%). The in-hospital mortality of patients with NFGNB, enteric, and Gram-positive bacterial pneumonias were $100 \%, 68 \%$, and $14 \%$, respectively. Using the Cox-proportional hazards model, we found that age $>75$ years (hazard ratio [HR], 1.98, 95\% confidence interval [95\% CI], 1.30-3.02), pre-ECMO dialysis (HR, 3.20, 95\% CI, 1.34-7.63), longer door-to-ECMO intervals (HR, 1.01, 95\% CI, 1.00-1.02), venoarterial mode (HR, 2.58, 95\% CI, 1.55-4.21), and fungal (HR, 2.83, 95\% CI, 1.365.88) and NFGNB sepsis (HR, 2.48, 95\% CI, 1.44-4.27) were associated with mortality. Gram-positive sepsis (HR, 0.20, 95\% CI, 0.08-0.57), myocarditis (HR, 0.12, 95\% CI, 0.06-0.27), pneumonia (HR, 0.54, 95\% CI, 0.30-0.90), and effective empirical antimicrobial therapy were predictive of survival (HR, 0.57, 95\% CI, 0.37-0.89); all $P<.05$. Excluding the 67 heavily premorbid patients, we found that $54 \%$ survived ECMO and $42 \%$ survived to discharge, with significantly more survivors with door-to-ECMO times of $\leq 96$ hours than $>96$ hours (59\% vs $15 \%, P<.0001)$.

Conclusions: Better outcomes were associated with door-to ECMO times of 96 hours or less, for Gram-positive rather than Gram-negative sepsis, and for pneumonia rather than primary bloodstream infections. (J Thorac Cardiovasc Surg 2016;152:1526-36)

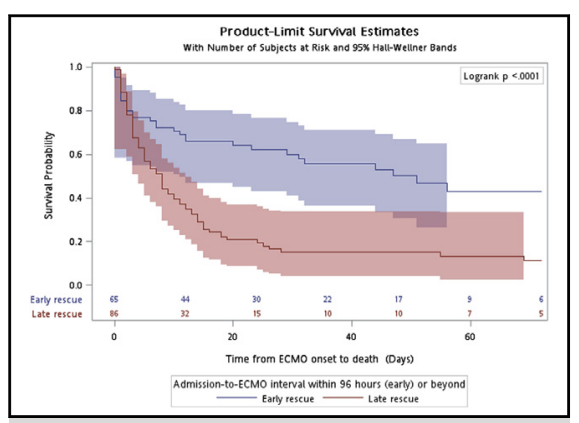

Early (within first 96 hours of admission) versus late rescue impacts survival on extracorporeal membrane oxygenation.

\section{Central Message}

If extracorporeal membrane oxygenation is to be applied to adults with sepsis, clinicians may wish to prioritize cases admitted within 4 days from the community.

\section{Perspective}

Little is known about the characteristics of infections predictive of the survival of adults with life-threatening sepsis undergoing extracorporeal membrane oxygenation. We found better outcomes were associated with door-to extracorporeal membrane oxygenation times of 96 hours or less, for Gram-positive rather than Gram-negative sepsis, and for pneumonia rather than primary bloodstream infections.

See Editorial page 1479.

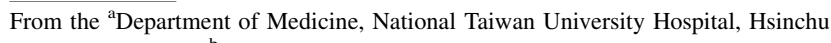
Branch, Hsinchu; ${ }^{b}$ Department of Medicine, National Taiwan University Hospital, Main Branch and College of Medicine; ${ }^{\circ}$ Department of Medicine, Far Eastern Memorial Hospital; ${ }^{\mathrm{d}}$ Department of Surgery, National Taiwan University Hospital and College of Medicine; and ${ }^{\mathrm{e}}$ International Harvard Statistical Consulting Company, Taipei, Taiwan.

Received for publication Nov 13, 2015; revisions received July 27, 2016; accepted for publication Aug 22, 2016; available ahead of print Sept 29, 2016.

Address for reprints: Shan-Chwen Chang, MD, PhD, Division of Infectious Diseases, Department of Medicine, National Taiwan University Hospital, 7 Chung-Shan South Rd, Taipei 100, Taiwan (E-mail: changsc@ntu.edu.tw).

$0022-5223 / \$ 36.00$

Copyright (c) 2016 by The American Association for Thoracic Surgery

http://dx.doi.org/10.1016/j.jtcvs.2016.08.038
Extracorporeal membrane oxygenation (ECMO) is an advanced means of life support for critically ill patients with refractory cardiac or respiratory failure. ${ }^{1,2}$ For the pediatric population with overall survival rates of $68 \%$ to $74 \%$, ECMO is considered effective as a rescue therapy

Scanning this QR code will take you to the supplemental information and video for this article.

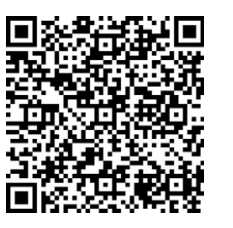




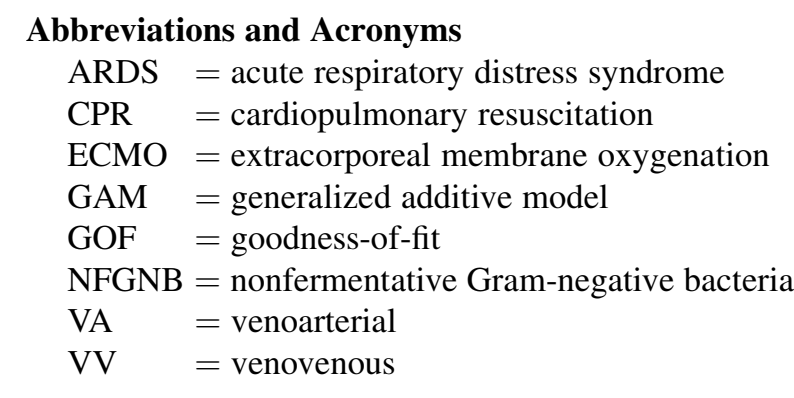

for severe sepsis when conventional management fails. ${ }^{3-5}$ For the adult population, however, the use of ECMO for refractory septic shock remains controversial because of reports of high mortality $(71 \%-78 \%))^{6,7}$

Despite unproven benefit, the relative lack of restrictions on ECMO use by our National Health Insurance and the pressure exerted on our center to salvage all referrals have resulted in a unique opportunity to study an unusually expansive cohort of septic adults supported by ECMO during the last decade. Efforts to identify the risk factors associated with unfavorable outcomes on ECMO for adults with septic shock have been limited, although preserved left ventricular function has been proposed as one such risk factor. ${ }^{7,8}$ Because ECMO acts as a bridge rather than a cure for shock, we hypothesized that factors related to the underlying infection determining its reversibility would impact survival outcomes. In this descriptive observational study, we aimed to identify patient- and infection-related factors that are associated with survival to improve on our suboptimal outcomes, provide a valid basis for restricting unrealistic candidates, and generate hypotheses for future experimental trials.

\section{METHODS}

Cases were identified from the National Taiwan University Hospital ECMO registry. The National Taiwan University Hospital has provided extracorporeal life support since 1994, with current cases approximating 100 annually. ${ }^{9,10}$ The equipment and standardized management of cases have been detailed previously (see Appendix E1; Video 1). ${ }^{1-13}$ The data of all patients receiving ECMO were collated prospectively into our database and reported to the Extracorporeal Life Support Organization. Patients were included if they were 16 years or older, underwent ECMO between January 1, 2001 and December 31, 2011, and required ECMO for infection-related acute respiratory distress syndrome (ARDS) or severe septic shock refractory to maximal conventional therapy. Patients were excluded if this was not their first $\mathrm{ECMO}$ or if ECMO was initiated off-site, to minimize underestimation of infections secondary to incomplete surveillance.

In the secondary analysis on outcomes of septic adults receiving ECMO stratified by days from admission to ECMO onset, patients $>75$ years of age with end-stage heart failure or renal disease on dialysis, on active immunosuppressive therapy for their organ transplantation or autoimmune diseases, and with active cancers were excluded from the analysis, because many ECMO centers would not have considered these patients as potential candidates because of their low likelihoods of disease reversibility and negligible gains in quality of life-years. Inhaled nitric oxide, highfrequency oscillatory ventilation, and intra-aortic balloon counterpulsation were available as adjunctive supportive therapies at this center. The final

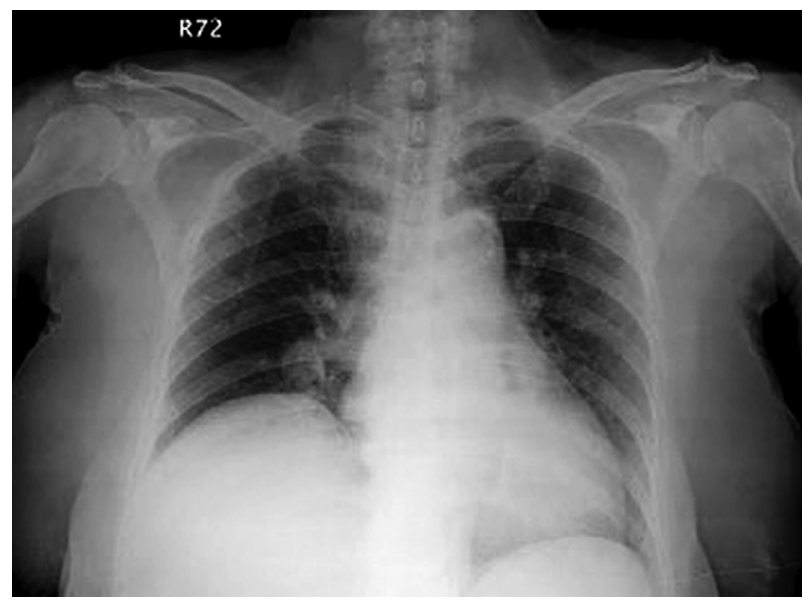

VIDEO 1. Emergent set-up of a venoarterial extracorporeal membrane oxygenation circuit via the femoral route in an elderly patient with massive pulmonary embolism requiring continuous cardiopulmonary resuscitation to bridge to open thrombectomy. Video available at: http://www. jtcvsonline.org/article/S0022-5223(16)31068-6/addons.

decision to initiate ECMO was at the discretion of the ECMO specialist team and the primary care physician.

The ECMO mode was categorized as venoarterial (VA) or venovenous (VV). Septic patients with ARDS and concomitant shock not meeting the criteria for VA-ECMO received VV-ECMO preferentially. At ECMO initiation, severe ARDS was defined by the acute onset $(<1$ week) of bilateral chest infiltrates and the sustained need ( $>12$ hours) for $100 \%$ fractional inspired oxygen under which the $\mathrm{PaO}_{2}$ was $100 \mathrm{~mm} \mathrm{Hg}$ or less under positive end-expiratory pressure of at least $5 \mathrm{cmH}_{2} \mathrm{O}$ and retrospectively confirmed by the Berlin definition. Refractory septic shock indication was defined by the requirement for sustained cardiopulmonary resuscitation (CPR), inability to maintain mean arterial pressure greater than $60 \mathrm{~mm} \mathrm{Hg}$, or progressive lactic acidosis and end-organ dysfunction despite fluid resuscitation and 2 or more continuous infusions of high-dose inotropes ( $>2$ hours) in the context of severe sepsis. Dopamine or dobutamine infusions greater than $20 \mu \mathrm{g} \mathrm{kg}^{-1} \mathrm{~min}^{-1}$ and norepinephrine and epinephrine infusions greater than $0.5 \mu \mathrm{g} \mathrm{kg}^{-1} \mathrm{~min}^{-1}$ typically were considered high doses. The inotrope equivalent score was calculated from the dosages of dopamine + dobutamine (in $\mu \mathrm{g} \mathrm{kg}^{-1} \mathrm{~min}^{-1}$ ) + (dosages of epinephrine + norepinephrine + isoproterenol [in $\mu \mathrm{g} \mathrm{kg}^{-1}$ $\left.\left.\min ^{-1}\right]\right) \times 100+$ dosages of milrinone (in $\left.\mu \mathrm{g} \mathrm{kg}^{-1} \min ^{-1}\right) \times 15$ to quantify the sum of the inotropes being infused when the ECMO was applied.

Patients routinely received septic workup at ECMO onset, including 2 sets of blood cultures, chest radiograph, and culture of sites as indicated. The Centers for Disease Control and Prevention/National Health Surveillance Network criteria for infections in the acute care settings were used to classify infections (Appendix E1; Video 1). ${ }^{14}$ Two infectious disease clinicians independently reviewed and discussed the medical records to reach an agreement in cases of dispute. The institutional review board waived the need for informed consent. The primary outcome was in-hospital mortality.

\section{Statistical Methods}

Analysis was performed with the R 3.2.4 software (R Project for Statistical Computing, Vienna, Austria). A 2 -sided $P$ value $\leq .05$ was considered statistically significant. The end point of this study was the time (in days) from the onset of ECMO to in-hospital death. The alive patient remained at risk whether on or off ECMO throughout the hospital course. The follow-up time ended when the patient died in the hospital or when the patient was discharged alive from the hospital. The distributional properties of continuous variables were expressed by 
TABLE 1. Clinical characteristics of 151 adults with life-threatening infections on ECMO

\begin{tabular}{|c|c|c|c|c|}
\hline Variables & All $(\mathbf{n}=151)$ & Survivors $(n=45)$ & Nonsurvivors $(\mathbf{n}=106)$ & $P$ value \\
\hline Age, y, \% (n) & & & & .075 \\
\hline $16-30$ & $18.5(28)$ & $39.3(11)$ & $60.7(17)$ & \\
\hline $31-45$ & $21.9(33)$ & $39.4(13)$ & $60.6(20)$ & \\
\hline $46-65$ & $39.1(59)$ & $28.8(17)$ & $71.2(42)$ & \\
\hline$>65$ & $20.5(31)$ & $12.9(4)$ & $87.1(27)$ & \\
\hline Median (25th-75th percentiles) & $51(37-63)$ & $43(29-55)$ & $55(41-66)$ & .006 \\
\hline Male, $\%(n)$ & $66.2(100)$ & $28.0(28)$ & $72.0(72)$ & .498 \\
\hline Initial body mass index, mean (SD), $\mathrm{kg} / \mathrm{m}^{2}$ & $23.5(4.0)$ & $24.2(5.0)$ & $23.2(3.5)$ & .198 \\
\hline \multicolumn{5}{|l|}{ Underlying diseases, \% (n) } \\
\hline Charlson comorbidity index, mean (SD) & $2.5(2.5)$ & $1.6(1.7)$ & $2.9(2.8)$ & .007 \\
\hline Congestive heart failure, NYHA II-IV & $74.2(112)$ & $25.9(29)$ & $74.1(83)$ & .055 \\
\hline Hypertension & $23.2(35)$ & $31.4(11)$ & $68.6(24)$ & .810 \\
\hline Diabetes mellitus & $21.9(33)$ & $21.2(7)$ & $78.8(26)$ & .222 \\
\hline Active malignancy & $17.9(27)$ & $14.8(4)$ & $85.2(23)$ & .060 \\
\hline Transplantation & $15.2(23)$ & $17.4(4)$ & $82.6(19)$ & .158 \\
\hline Coronary artery disease & $14.6(22)$ & $9.1(2)$ & $90.0(20)$ & .022 \\
\hline Autoimmune disease & $6.0(9)$ & $0.0(0)$ & $100.0(9)$ & .058 \\
\hline Chronic lung disease & $4.0(6)$ & $16.7(1)$ & $83.3(5)$ & .670 \\
\hline Remote ischemic stroke & $3.3(5)$ & $0.0(0)$ & $100.0(5)$ & .437 \\
\hline Remote intracranial hemorrhage & $5.3(8)$ & $12.5(1)$ & $87.5(7)$ & .322 \\
\hline Cirrhosis of the liver & $3.3(5)$ & $20.0(1)$ & $80.0(4)$ & 1.000 \\
\hline Pre-ECMO dialysis & $4.6(7)$ & $0.0(0)$ & $100.0(7)$ & .104 \\
\hline \multicolumn{5}{|l|}{ Initial disease severity, mean (SD) } \\
\hline APACHE II & $22.8(9.2)$ & $20.3(7.9)$ & $23.8(9.9)$ & .002 \\
\hline SOFA I & $12.6(4.6)$ & $12.3(4.3)$ & $13.3(4.5)$ & .195 \\
\hline Inotropic equivalent score* & $64.4(132.3)$ & $40.0(57.0)$ & $75.2(152.4)$ & .036 \\
\hline Serum lactate at ECMO onset, $\mathrm{mmol} / \mathrm{L}$ & $7.2(5.3)$ & $5.7(4.0)$ & $7.9(5.7)$ & .026 \\
\hline Serum lactate $24 \mathrm{~h}$ after ECMO, mmol/L & $7.3(5.8)$ & $6.2(5.4)$ & $7.9(6.0)$ & .178 \\
\hline Indications for ECMO, \% (n) & & & & .441 \\
\hline ARDS & $39.7(60)$ & $33.3(20)$ & $66.7(40)$ & \\
\hline PF ratio, $\dagger$ mean (SD) & $82.3(50.9)$ & $82.3(48.2)$ & $82.2(52.1)$ & 1.000 \\
\hline Refractory septic shock & $60.3(91)$ & $27.5(25)$ & $72.5(66)$ & \\
\hline Cardiac index,$\ddagger$ mean $(\mathrm{SD}) \mathrm{L} / \mathrm{min} / \mathrm{m}^{2}$ & $2.1(1.9)$ & $1.0(0.2)$ & $4.24(2.0)$ & .040 \\
\hline Cardiac output, mean (SD) L/min & $3.8(2.3)$ & $2.7(2.2)$ & $5.6(0.4)$ & .065 \\
\hline $\mathrm{SVRI}, \oint$ dynes.s $/ \mathrm{cm}^{5} / \mathrm{m}^{2}$ & $3883.4(3545.5)$ & $5364.2(3757.6)$ & $1282.0(368.6)$ & .119 \\
\hline SVR, dynes.s $/ \mathrm{cm}^{5}$ & $2550.9(2337.5)$ & $3273.0(2430.9)$ & $745.5(145.0)$ & .224 \\
\hline ECMO mode, $\%(n)$ & & & & .054 \\
\hline Venoarterial & $66.9(101)$ & $24.8(25)$ & $75.2(76)$ & \\
\hline Venovenous & $33.1(50)$ & $40.0(20)$ & $60.0(30)$ & \\
\hline \multicolumn{5}{|l|}{ Clinical course, mean (SD), d } \\
\hline Admission to ECMO interval & $17.2(24.7)$ & $8.1(15.1)$ & $20.0(25.0)$ & $<.001$ \\
\hline ECMO start to death & $11.3(16.9)$ & N/A & $11.3(16.9)$ & N/A \\
\hline Mechanical ventilation to ECMO interval & $8.1(31.5)$ & $4.5(8.0)$ & $9.5(37.0)$ & .368 \\
\hline Duration of ECMO use & $7.9(8.6)$ & $9.8(5.9)$ & $6.9(9.6)$ & .243 \\
\hline Total duration of mechanical ventilation & $23.2(35.4)$ & $28.1(22.1)$ & $21.0(39.7)$ & .270 \\
\hline \multicolumn{5}{|l|}{ Cardiac events, \% (n) } \\
\hline CPR before ECMO installation & $24.5(37)$ & $24.3(9)$ & $75.7(28)$ & .402 \\
\hline CPR during ECMO installation & $19.2(29)$ & $27.6(8)$ & $72.4(21)$ & .772 \\
\hline Types of Infections \% (n) & & & & $<.001$ \\
\hline Pneumonia & $50.3(76)$ & $23.7(18)$ & $76.3(58)$ & \\
\hline Primary bloodstream & $14.6(22)$ & $4.5(1)$ & $95.5(21)$ & \\
\hline Intra-abdominal infection & $7.9(12)$ & $25.0(3)$ & $75.0(9)$ & \\
\hline Acute myocarditis & $19.9(30)$ & $63.3(19)$ & $36.7(11)$ & \\
\hline
\end{tabular}


TABLE 1. Continued

\begin{tabular}{|c|c|c|c|c|}
\hline Variables & All $(\mathbf{n}=151)$ & Survivors $(n=45)$ & Nonsurvivors $(n=106)$ & $P$ value \\
\hline Types of pathogens, \% (n) & & & & .006 \\
\hline Gram-positive cocci & $17.2(26)$ & $38.5(10)$ & $61.5(16)$ & \\
\hline Gram-negative bacilli & $33.8(51)$ & $15.8(8)$ & $84.3(43)$ & \\
\hline Fungi & $6.6(10)$ & $10.0(1)$ & $90.0(9)$ & \\
\hline Virus & $17.2(26)$ & $57.7(15)$ & $43.3(11)$ & \\
\hline Polymicrobial & $10.6(16)$ & $12.5(2)$ & $87.5(14)$ & \\
\hline Unknown pathogen & $25.2(38)$ & $21.1(8)$ & $78.9(30)$ & \\
\hline Effective antimicrobials, \% (n) & $41.1(62)$ & $29.0(18)$ & $71.0(44)$ & $>.999$ \\
\hline \multicolumn{5}{|l|}{ Complications on ECMO, \% (n) } \\
\hline ECMO circuit clot & $42.4(64)$ & $34.4(22)$ & $65.6(42)$ & .292 \\
\hline Major bleeding & $16.6(25)$ & $36.0(9)$ & $64.0(16)$ & .458 \\
\hline Post-ECMO neurologic deficit & $14.6(22)$ & $4.5(1)$ & $95.5(21)$ & .005 \\
\hline Survived with neurologic disability & $9.3(14)$ & $100(14)$ & N/A & N/A \\
\hline Pneumothorax & $7.3(11)$ & $27.3(3)$ & $72.7(8)$ & 1.000 \\
\hline Post-ECMO dialysis dependence & $51.0(77)$ & $23.4(18)$ & $76.6(59)$ & .078 \\
\hline Hypoglycemia & $4.0(6)$ & $0(0)$ & $100.0(6)$ & .177 \\
\hline Peripheral limb ischemia & $40.4(61)$ & $23.0(14)$ & $77.0(47)$ & .130 \\
\hline \multicolumn{5}{|l|}{ Transfusion within first $72 \mathrm{~h}$, mean units (SD) } \\
\hline Whole blood & $0.3(1.2)$ & $0.1(0.5)$ & $0.3(1.4)$ & .136 \\
\hline Packed red blood cells & $5.6(6.2)$ & $4.3(3.2)$ & $6.2(7.0)$ & .024 \\
\hline Fresh-frozen plasma & $2.1(4.3)$ & $0.9(2.5)$ & $2.5(4.8)$ & .009 \\
\hline Platelet & $9.4(15.1)$ & $4.9(6.9)$ & $11.3(17.2)$ & .001 \\
\hline \multicolumn{5}{|l|}{ Survival outcomes, \% (n) } \\
\hline In-hospital mortality & $70.2(106)$ & N/A & N/A & N/A \\
\hline Survived beyond ECMO & $45.0(68)$ & N/A & N/A & N/A \\
\hline Discharged alive & $29.8(45)$ & N/A & N/A & N/A \\
\hline Discharged without neurologic sequelae & $68.9(31 / 45)$ & N/A & N/A & N/A \\
\hline
\end{tabular}

SD, Standard deviation; NYHA II-IV, New York Heart Association class II-IV; ECMO, extracorporeal membrane oxygenation; APACHE II, acute physiology and chronic health evaluation II score; SOFA I, Sequential Organ Failure Assessment I; ARDS, acute respiratory distress syndrome; SVRI, systemic vascular resistance index; SVR, systemic vascular resistance; $N / A$, not available; $C P R$, cardiopulmonary resuscitation. *Inotrope equivalent score was calculated from the dosages of dopamine + dobutamine (in $\mu \mathrm{g} / \mathrm{kg} / \mathrm{min})+($ dosages of epinephrine + norepinephrine + isoproterenol [in $\mu \mathrm{g} / \mathrm{kg} / \mathrm{min}]) \times 100+$ dosages of milrinone (in $\mu \mathrm{g} / \mathrm{kg} / \mathrm{min}) \times 15$. The score here quantified the inotropes being infused when the ECMO was applied. $\nmid \mathrm{PF}$ ratio $=\mathrm{PaO}_{2} / \mathrm{FiO}_{2}$ ratio is the ratio of arterial oxygen partial pressure to fractional inspired oxygen and was only calculated for patients receiving ECMO for ARDS. $\ddagger$ Cardiac index = is a measure of the cardiac output expressed as a flow per body surface area only calculated for patients receiving ECMO for refractory shock. Data were missing in 8 patients. $§$ Data were missing in 8 patients.

mean \pm standard deviation, median, and 25th and 75th percentiles; categorical variables were presented by frequency and percentage; and the survival curve of time to death was estimated by the Kaplan-Meier method. In univariate analysis, the unadjusted effect of each potential prognostic factors of the survival time was examined with Wilcoxon rank-sum test and Fisher exact test as appropriate for the data type. Next, multivariate analysis was conducted by fitting Cox proportional hazards model to estimate the adjusted effects of prognostic factors on survival time.

To ensure the analysis quality, basic model-fitting techniques for (1) variable selection, (2) goodness-of-fit (GOF) assessment, and (3) regression diagnostics and remedies were used in our regression analyses. Specifically, the stepwise variable selection procedure (with iterations between the forward and backward steps) was applied to obtain the best candidate final regression model. All the univariate significant and nonsignificant relevant covariates (listed in Table 1) and some of their interaction terms (or moderators) were put on the variable list to be selected. The significance levels for entry and for stay were set to 0.15 for being conservative.

The GOF measures, including concordance and adjusted generalized $\mathrm{R} 2$, were examined to assess the GOF of the fitted Cox proportional hazards model. Simple and multiple generalized additive models (GAMs) were fitted to detect nonlinear effects of continuous covariates and identify appropriate cut-off point(s) for discretizing continuous covariates, if necessary, during the stepwise variable selection procedure. Computationally, the vgam function (with the default values of smoothing parameters) of the VGAM package (R Project for Statistical Computing) was used to fit GAMs for continuous, binary, and count responses in R. Finally, the statistical tools of regression diagnostics for verification of proportional hazards

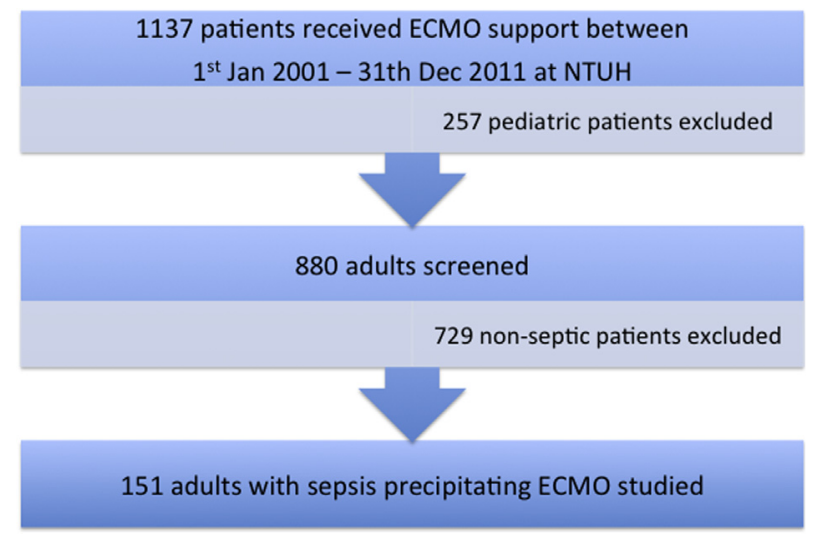

FIGURE 1. Flow diagram of patient selection. ECMO, Extracorporeal membrane oxygenation; NTUH, National Taiwan University Hospital. 


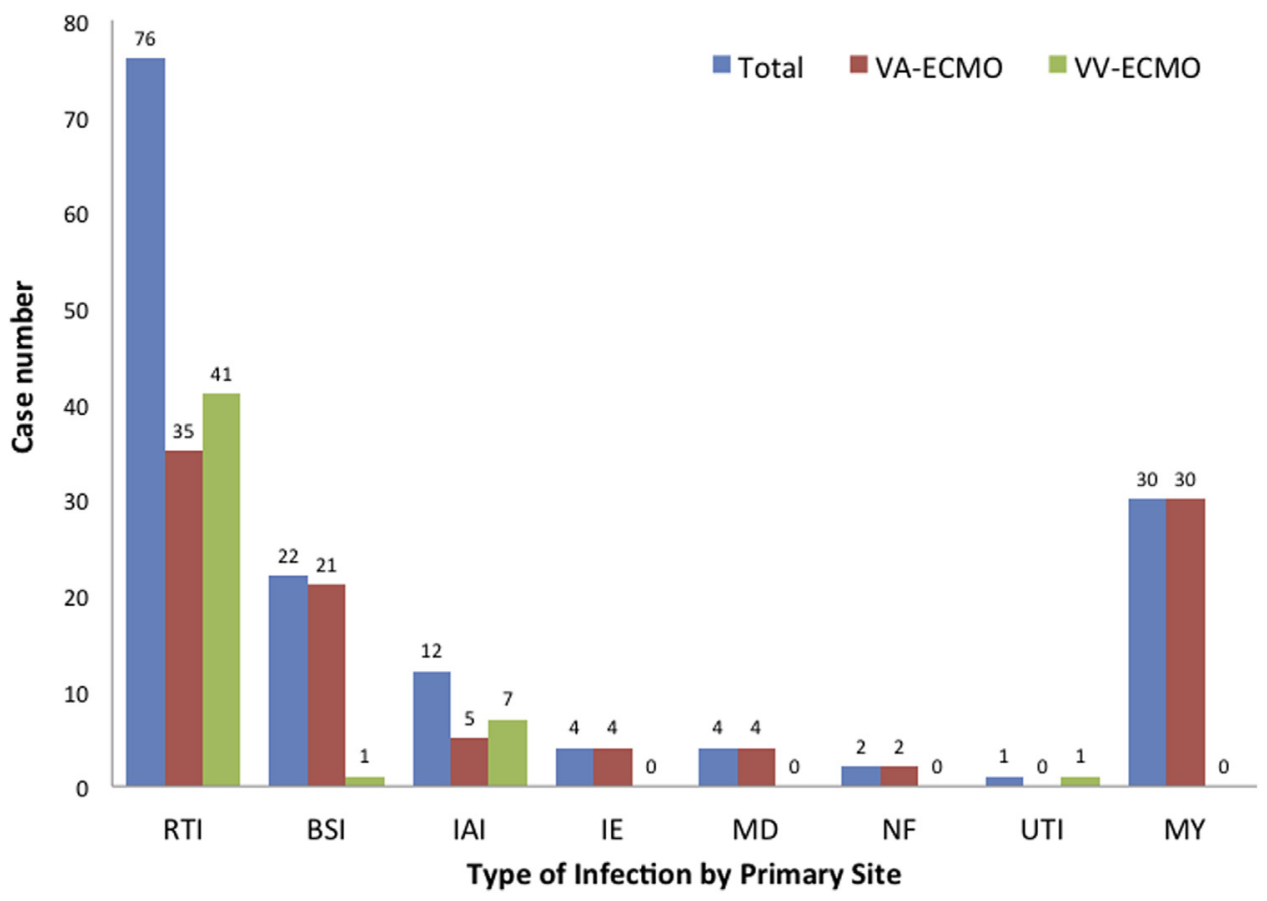

FIGURE 2. The types of life-threatening infections in 151 septic adults receiving extracorporeal life support between 2001 and 2011 classified by primary site of infection and mode of extracorporeal life support. VA, Venoarterial; ECMO, extracorporeal membrane oxygenation; VV, venovenous; $R T I$, respiratory tract infection; $B S I$, primary bloodstream infection; $I A I$, intra-abdominal infection; $I E$, infective endocarditis; $M D$, mediastinitis; $N F$, necrotizing fasciitis; $U T I$, bacteremic urinary tract infection; $M Y$, myocarditis.

assumption, residual analysis, detection of influential cases, and check of multicollinearity were applied to discover any model or data problems. The values of variance inflating factor $\geq 10$ in continuous covariates or $\geq 2.5$ in categorical covariates indicate the occurrence the multicollinearity problem among some of the covariates in the fitted regression model.

\section{RESULTS}

During the study period, 1137 patients underwent ECMO for the first time at this institution (Figure 1). After we excluded pediatric patients and nonseptic adult patients, 151 adults with sepsis precipitating ECMO were studied. The demographics and clinical characteristics of the cohort are shown in Table 1. Two-thirds of the patients were male, and the median age was 51 years (25th-75th percentiles were 37-63 years); however, one-fifth of the cohort was older than 65 years at initiation of extracorporeal life support. Initial disease severity and vasopressor demand as measured by the Acute Physiology and Chronic Health Evaluation II, Sequential Organ Failure Assessment, inotropic equivalent scores, and serum lactate were high with mean values of $22.8,12.6,64.4$, and $7.2 \mathrm{mmol} / \mathrm{L}$, respectively. The mean $\mathrm{PaO}_{2} /$ fraction of inspired oxygen ratio for patients with ARDS was 82.3, and the mean cardiac index for patients with refractory shock was $2.1 \mathrm{~L} / \mathrm{min} / \mathrm{m}^{2}$. Ninety-one patients with refractory shock in addition to 10 patients with ARDS and severe septic shock received VA-ECMO (66.9\%). The remaining 50 patients with ARDS were managed with VV-ECMO $(33.1 \%)$ and conventional vasopressors. The prominent comorbidities were congestive heart failure $(74.8 \%)$, hypertension $(23.2 \%)$, diabetes mellitus $(21.9 \%)$, active malignancy $(17.9 \%)$, and hematologic or solid-organ transplantation $(15.2 \%)$.

\section{Infection Sites and Pathogens}

The primary infection sites (Figure 2) were pneumonia $(50.3 \%)$, acute myocarditis $(19.9 \%)$, primary bloodstream infections $(14.6 \%)$, intra-abdominal infections $(7.9 \%)$, infective endocarditis (2.6\%), mediastinitis (2.6\%), necrotizing fasciitis $(1.3 \%)$, and post-transrectal prostate biopsy urosepsis $(0.7 \%)$. Pathogens were identified for the majority of these infections $(74.8 \%)$, with more than one pathogen isolated from 16 of the patients. Of a total of 126 isolates of which 53 were blood isolates, $33(26.2 \%)$ were nonfermentative Gram-negative bacteria (NFGNB), $27(21.4 \%)$ were enteric Gramnegative bacteria, $26(20.6 \%)$ were Gram-positive cocci, $25(19.8 \%)$ were viruses, $10(7.9 \%)$ were fungi, 4 $(3.2 \%)$ were anaerobic bacteria, and $1(0.8 \%)$ was a mycobacterium (Table 2). The most common pathogens for the aforementioned categories were Pseudomonas aeruginosa, Klebsiella pneumoniae, methicillin-resistant 
TABLE 2. Pathogens isolated from 151 patients with severe sepsis salvaged on extracorporeal membrane oxygenation

\begin{tabular}{|c|c|c|c|c|c|c|}
\hline \multirow[b]{2}{*}{ Site (n) } & \multicolumn{6}{|c|}{ Types of pathogen (n) } \\
\hline & NFGNB & EGNB & GPC & Virus & Fungi & Others \\
\hline \multirow[t]{4}{*}{ RTI (76) } & $\begin{array}{l}\text { Pseudomonas } \\
\quad \text { aeruginosa }(15)\end{array}$ & $\begin{array}{l}\text { Klebsiella } \\
\quad \text { pneumoniae (5) }\end{array}$ & MRSA (4) & Influenza (4) & Pneumocystis (3) & Mycobacterium kansasii (1) \\
\hline & $\begin{array}{l}\text { Acinetobacter } \\
\text { baumannii (10) }\end{array}$ & $\begin{array}{l}\text { Morganella } \\
\quad \text { morganii (2) }\end{array}$ & MSSA (1) & CMV (3) & Aspergillus (2) & Unknown (22) \\
\hline & $\begin{array}{c}\text { Stenotrophomonas } \\
\text { maltophilia (2) }\end{array}$ & Escherichia coli (1) & Pneumococcus (2) & HSV (1) & Acremonium (1) & \\
\hline & $\begin{array}{l}\text { Burkholderia } \\
\quad \text { cepacia }(1) \\
\text { Elizabethkingia } \\
\quad \text { meningoseptica }(1)\end{array}$ & $\begin{array}{l}\text { Serratia } \\
\quad \text { marcescens (1) }\end{array}$ & & & & \\
\hline \multirow[t]{5}{*}{ BSI (22) } & & K pneumoniae (4) & MRSA (3) & & Candida albicans (1) & Lactobacillus (1) \\
\hline & & $E \operatorname{coli}(2)$ & MSSA (3) & & Candida tropicalis (1) & \\
\hline & & Enterobacter (1) & MRCONS (3) & & & \\
\hline & & Salmonella (1) & $\begin{array}{l}\text { Streptococcus } \\
\quad \text { constellatus }(2)\end{array}$ & & & \\
\hline & & $S$ marcescens (1) & Enterococcus (2) & & & \\
\hline \multirow[t]{2}{*}{ IAI (12) } & P aeruginosa (3) & K pneumoniae (6) & Streptococcus & & & Bacteriodes fragilis (1) \\
\hline & & E coli $(1)$ & anginosus (1) & & & Peptostreptococcus (1) \\
\hline IE (4) & & K pneumoniae (1) & MRCONS (1) & & Candida albicans (1) & Culture negative (1) \\
\hline \multirow[t]{2}{*}{ MD (4) } & $S$ maltophilia (1) & & MRSA (1) & & Candida tropicalis (1) & Fusobacterium \\
\hline & & & $S$ constellatus (1) & & & nucleatum (1) \\
\hline \multirow[t]{2}{*}{ NF (2) } & & & $\begin{array}{l}\text { Streptococcus } \\
\text { pyogenes }(1)\end{array}$ & & & \\
\hline & & & Enterococcus (1) & & & \\
\hline UTI (1) & & ESBL $E$ coli $(1)$ & & & & \\
\hline \multirow[t]{2}{*}{ MY (30) } & & & & Enteroviruses (3) & & Unknown (12) \\
\hline & & & & Other viruses (15) & & \\
\hline
\end{tabular}

NFGNB, Nonfermentative Gram-negative bacilli; $E G N B$, enteric Gram-negative bacilli; $G P C$, Gram-positive cocci; $R T I$, respiratory tract infection; $M R S A$, methicillin-resistant $S$ aureus; MSSA, methicillin-susceptible $S$ aureus; CMV, cytomegalovirus; HSV, herpes simplex virus; BSI, primary bloodstream infection; MRCONS, methicillin-resistant coagulase-negative staphylococci; $I A I$, intra-abdominal infection; $I E$, infective endocarditis; $M D$, mediastinitis; $N F$, necrotizing fasciitis; $U T I$, bacteremic urinary tract infection; ESBL E coli, extended-spectrum beta-lactamase producing $E$ coli; $M Y$, myocarditis.

Staphylococcus aureus, influenza virus, and Candida species (Table 2). When the pathogens were grouped according to the timing of ECMO onset, all fungal, mycobacterial and most NFGNB pathogens were identified from patients receiving ECMO after the first 4 days of admission whereas influenza, streptococcal, and staphylococcal infections predominated among those receiving ECMO within the first 4 days of admission (Table 3).

TABLE 3. Pathogens isolated from 151 patients stratified by the time from admission to septic event precipitating rescue with extracorporeal membrane oxygenation

\begin{tabular}{|c|c|c|c|c|c|c|}
\hline & \multicolumn{6}{|c|}{ Types of pathogen (n) } \\
\hline & NFGNB & EGNB & GPC & Virus & Fungi & Others \\
\hline $\begin{array}{l}\text { Early (within } \\
\text { first } 96 \mathrm{~h} \text { ) }\end{array}$ & P aeruginosa (4) & $\begin{array}{l}\text { K pneumoniae }(5) \\
\text { E coli }(2) \\
\text { S marcescens }(1)\end{array}$ & $\begin{array}{l}\text { MRSA (2) } \\
\text { MSSA (2) } \\
\text { Pneumococcus (1) } \\
\text { S constellatus (2) } \\
\text { S anginosus (1) } \\
\text { S pyogenes (1) }\end{array}$ & $\begin{array}{l}\text { Influenza (3) } \\
\text { Enterovirus (3) } \\
\text { Other viruses (15) }\end{array}$ & None $(0)$ & Unknown (16) \\
\hline $\begin{array}{l}\text { Late (beyond } \\
\quad \text { first } 96 \mathrm{~h} \text { ) }\end{array}$ & $\begin{array}{l}\text { P aeruginosa }(14) \\
\text { A baumannii }(10) \\
\text { S maltophilia }(3) \\
\text { B cepacia }(1) \\
\text { C meningosepticum }(1)\end{array}$ & $\begin{array}{l}\text { K pneumoniae }(11) \\
\text { E coli }(3) \\
\text { Enterobacter }(1) \\
\text { Salmonella }(1) \\
\text { S marcescens }(1) \\
\text { M morganii }(2)\end{array}$ & $\begin{array}{l}\text { MRSA (6) } \\
\text { MSSA (2) } \\
\text { MRCONS (4) } \\
\text { Pneumococcus (1) } \\
\text { Enterococcus (3) } \\
\text { S constellatus (1) }\end{array}$ & $\begin{array}{l}\text { CMV (3) } \\
\text { HSV (1) } \\
\text { Influenza (1) }\end{array}$ & $\begin{array}{l}\text { Candida albicans (2) } \\
\text { Candida tropicalis (2) } \\
\text { Pneumocystis (3) } \\
\text { Aspergillus (2) } \\
\text { Acremonium (1) }\end{array}$ & $\begin{array}{l}\text { B fragilis (1) } \\
\text { F nucleatum (1) } \\
\text { Peptostreptococcus (1) } \\
\text { Lactobacillus (1) } \\
\text { M kansasii (1) } \\
\text { Unknown (18) }\end{array}$ \\
\hline
\end{tabular}

NFGNB, Nonfermentative Gram-negative bacilli; EGNB, enteric Gram-negative bacilli; GPC, Gram-positive cocci; MRSA, methicillin-resistant $S$ aureus; MSSA, methicillinsusceptible $S$ aureus; MRCONS, methicillin-resistant coagulase-negative staphylococci; $C M V$, cytomegalovirus; $H S V$, herpes simplex virus. 
TABLE 4. Multivariate analysis of 151 septic adults salvaged by ECMO for identifying the risk factors of time to hospital death using the Cox model

\begin{tabular}{|c|c|c|c|c|c|c|}
\hline Variables & References & HR $(95 \%$ CI $)$ & Estimate & Standard error & $z$ & $P$ value \\
\hline Age $>75 y^{*}$ & Age $\leq 75$ y & $1.98(1.30-3.02)$ & 0.685 & 0.214 & 3.195 & .001 \\
\hline Admission-to-ECMO duration $\times$ time & Per additional day & $1.01(1.00-1.02)$ & 0.009 & 0.004 & 2.101 & .036 \\
\hline Pre-ECMO dialysis & No dialysis & $3.20(1.34-7.63)$ & 1.164 & 0.443 & 2.626 & .009 \\
\hline Pneumonia & Primary BSI & $0.54(0.30-0.90)$ & -0.610 & 0.258 & -2.365 & .018 \\
\hline Myocarditis $\dagger$ & Primary BSI.v $\dagger$ & $0.12(0.06-0.27)$ & -2.097 & 0.398 & -5.269 & $<.001$ \\
\hline Gram-positive cocci & Enteric GNB & $0.20(0.08-0.57)$ & -1.569 & 0.518 & -3.031 & .002 \\
\hline Nonfermentative GNB & Enteric GNB & $2.48(1.44-4.27)$ & 0.908 & 0.278 & 3.265 & .001 \\
\hline Fungi & Enteric GNB & $2.83(1.36-5.88)$ & 1.041 & 0.373 & 2.793 & .005 \\
\hline Effective antimicrobial & Ineffective treatment & $0.57(0.37-0.89)$ & -0.563 & 0.227 & -2.481 & .013 \\
\hline CPR during ECMO & No CPR & $2.79(1.55-5.03)$ & 1.027 & 0.300 & 3.418 & $<.001$ \\
\hline Veno-arterial mode & Veno-venous mode & $2.58(1.58-4.21)$ & 0.948 & 0.250 & 3.798 & $<.001$ \\
\hline
\end{tabular}

The listed final multiple Cox model with one time-dependent interaction term (due to nonproportional hazard) was fitted to the 151 septic patients. The time-dependent interaction term in the Cox model indicated that the hazard rate of the admission-to-ECMO interval on the time to hospital death from ECMO onset would be increased as time (in days) went on. The goodness-of-fit measures, adjusted generalized $R^{2}=0.4799>0.15$, and concordance $=0.7674>0.7$ indicated a good fit because the value of the first measure is usually low. $H R$, Hazard ratio; $C I$, confidence interval; ECMO, extracorporeal membrane oxygenation; $B S I$, primary bloodstream infection; GNB, Gram-negative bacteria; $C P R$, cardiopulmonary resuscitation. *The generalized additive model was applied to detect nonlinear effects of continuous covariates such as age, and found that the risk associated with time to death increased sharply after 75 years. $\dagger$ Myocarditis - all patients with myocarditis received the venoarterial ECMO mode (ie, nested within the venoarterial mode) so that the reference group would be patients who had primary bloodstream infections and received venovenous mode.

\section{Outcomes and Associated Factors}

In the univariate analysis of characteristics distinguishing survivors from non-survivors (Table 1), survivors were significantly younger, admitted for shorter intervals preceding ECMO, less likely to have end-stage heart failure, coronary artery disease, autoimmune disease, active malignancy, or dialysis requirement at ECMO onset. In addition, survivors had lower initial Acute Physiology and Chronic Health Evaluation II scores (20.3 vs 23.8), cardiac indices ( $1.0 \mathrm{vs} 4.24 \mathrm{~L} / \mathrm{min} / \mathrm{m}^{2}$ ), initial serum lactate (5.7 vs $7.9 \mathrm{mmol} / \mathrm{L}$ ), composite vasopressors, and transfusion requirements. More than $50 \%$ of the patients with acute myocarditis survived compared with only $5 \%$ (ie, 1 of 22) of patients with bloodstream infections without an identified focus. There were significantly more survivors among patients with Gram-positive cocci infections, viral infections $(57.7 \%)$ than among those with fungal or Gram-negative sepsis (15.8\%).

In a multivariate analysis (Table 4), pre-ECMO factors including advanced age, dialysis, and longer admissionto-ECMO intervals were associated with increased odds of death, as were ECMO variables such as VA versus VV mode and CPR during ECMO. As for the types and sites of infections, Gram-positive sepsis was associated with survival, as were myocarditis and pneumonia compared with Gram-negative and primary bloodstream infections, respectively. Fungal and NFGNB sepsis compared with Gram-negative sepsis were associated independently with death whereas effective empirical antimicrobial therapy was associated with survival.

Using the receiver operating characteristic curve (data not shown), we determined the optimal cut-off of preECMO length of stay for predicting mortality to be 3.8 days (sensitivity $77.5 \%$, specificity $70.7 \%$ ). Because
3.8 days is impractical for decision making, we stratified these septic patients receiving extracorporeal support into those rescued early within 4 days of admission and those rescued late, that is, beyond 4 days of hospitalization. The Kaplan-Meier survival curves in Figure 3, A show significantly better outcomes for those rescued early than late. Of 151 patients, in-hospital mortality was $49 \%$ (32/65) among those rescued early and 86\% (74/86) among those rescued late.

In the secondary analysis of outcomes excluding patients older than 75 years or with immunocompromizing conditions such as advanced malignancy, end-stage cardiorenal failure, or chronic immunosuppressant use, 54\% (45/84) survived ECMO and $42 \%$ (35/84) patients survived to discharge (Figure 3, B). The overall survival rates of the well-selected patients were 59\% (30/51) if rescued early and $15 \%(5 / 34)$ if rescued late (Figure $3, B$ ).

\section{DISCUSSION}

The use of ECMO in adults with sepsis remains controversial, with limited published experience. To our knowledge, this is the largest retrospective single-center analysis of novel risk factors of mortality for septic adults in extremis receiving ECMO. ECMO was found to be more successful when applied to patients 75 years or younger and within the first 4 days of hospitalization, for life-threatening community-acquired infections such as staphylococcal or streptococcal septicaemia, acute myocarditis, severe community-acquired pneumonias, or influenza-associated ARDS, for which empirical antibiotics are more likely to be effective and recovery complete. Conversely, ECMO outcomes were poorer when applied after prolonged hospitalization, for infections caused by NFGNB or fungi, for bloodstream infections not secondary to an identified 


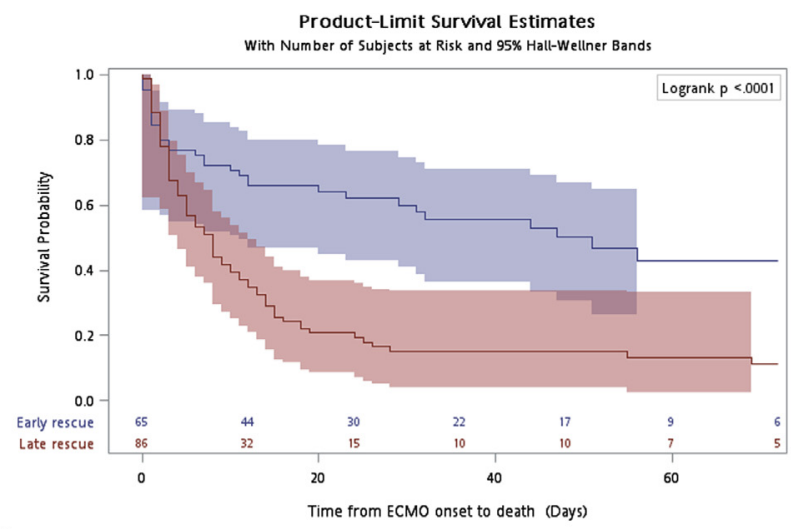

A

Admission-to-ECMO interval within 96 hours (early) or beyond

Admission-to-ECMO interval within 96 hours (early)
Early rescue $\longrightarrow$ Late rescue

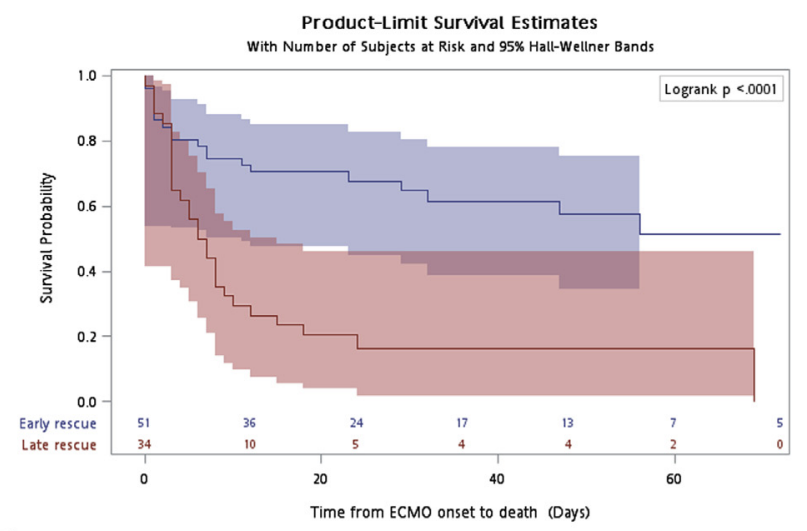

B

FIGURE 3. Kaplan-Meier estimate of the survival curves for early rescue (admission-to-ECMO onset within 96 hours) versus secondary or late rescue (admission-to-ECMO interval after the initial 96 hours of hospitalization). A, For the entire cohort of 151 septic adults. B, For the well-selected cohort aged 75 years or younger without end-stage comorbidities. ECMO, Extracorporeal membrane oxygenation.

focus, and for those who received CPR during the installation of ECMO. Putting these risk factors together, we identified typically poor candidates as patients admitted for primary events such as scheduled operations or chemotherapy who during the course of hospitalization developed a secondary nosocomial infection with a difficult-to-treat pathogen.

Among carefully selected ECMO candidates, survival rates were almost $60 \%$ with rescue within 4 days of admission but remained dismal $(15 \%)$ beyond that. Although delayed rescue has been intuitively linked to late, irreversible stages of organ failure, ${ }^{15}$ our study is the first to suggest that timing also distinguishes between host and microbiological factors. Traditionally, infections have been classified as community or hospital-acquired, according to their place of acquisition, and this classification is used to guide treatment decisions. ${ }^{13,14}$ The most often used definition of hospital-acquired infections are infections that were not present or incubating (ie, not occurring within 48 hours) at the time of admission. ${ }^{13,14}$ The distinction denotes differences in etiologies and in host characteristics with better outcomes in general being

TABLE 5. Summary of published studies of septic adults rescued with ECMO

\begin{tabular}{|c|c|c|c|c|c|c|c|c|}
\hline Study & No. & $\begin{array}{l}\text { Age, } \mathbf{y} \\
\text { (range) }\end{array}$ & $\begin{array}{c}\text { Previous } \\
\text { CPR } \\
\end{array}$ & $\begin{array}{l}\text { Underlying } \\
\text { condition }\end{array}$ & Sites of infection & Types of pathogen & $\begin{array}{c}\text { Predictors of } \\
\text { mortality identified }\end{array}$ & $\begin{array}{c}\text { Alive at } \\
\text { discharge }\end{array}$ \\
\hline $\begin{array}{l}\text { Brechot } \\
\text { et al, } \\
2013^{8}\end{array}$ & 14 & $45(28-66)$ & $0 \%$ & $\begin{array}{l}\text { SOT } 7.1 \% \\
\text { BMT } 0 \% \\
\text { Cancer } 14.3 \% \\
\text { Dialysis } 0 \%\end{array}$ & $\begin{array}{l}\text { Pneumonia } 78.6 \% \\
\text { Intra-abdominal } 14.3 \% \\
\text { Urinary tract } 0 \% \\
\text { Others } 7.1 \% \\
\text { Positive blood } \\
\quad \text { culture } 35.7 \%\end{array}$ & $\begin{array}{l}\text { GPC } 64.3 \% \\
\text { EGNB } 7.1 \% \\
\text { NFGNB } 21.4 \% \\
\text { Fungi } 0 \% \\
\text { Unknown } 7.1 \%\end{array}$ & $\begin{array}{l}\text { Refractory cardiovascular } \\
\text { dysfunction (descriptive } \\
\text { protective factor) }\end{array}$ & $\begin{array}{l}\text { Overall 71\% } \\
\text { GPC RTI } \\
\mathbf{8 3 . 3} \%(\mathbf{5} / \mathbf{6}) * \\
\text { NFGNB RTI } \\
33.3 \%(1 / 3)\end{array}$ \\
\hline $\begin{array}{l}\text { Park et al, } \\
2015^{7}\end{array}$ & 32 & $\begin{array}{c}55 \\
\text { (NA) }\end{array}$ & $43.8 \%$ & $\begin{array}{l}\text { SOT } 28.1 \% \\
\text { BMT } 6.3 \% \\
\text { Cancer } 15.6 \% \\
\text { Dialysis NA }\end{array}$ & $\begin{array}{l}\text { Pneumonia } 34.4 \% \\
\text { Intra-abdominal } 21.9 \% \\
\text { Urinary tract } 12.5 \% \\
\text { Others } 31.2 \% \\
\text { Positive blood } \\
\quad \text { culture } 62.5 \%\end{array}$ & $\begin{array}{l}\text { GPC } 34.4 \% \\
\text { EGNB } 28.2 \% \\
\text { NFGNB } 18.8 \% \\
\text { Fungi } 15.6 \% \\
\text { Unknown } 0 \%\end{array}$ & $\begin{array}{l}\text { CPR [aHR 4.61] } \\
\text { Peak Trop I > 15 ng/mL } \\
\quad \text { [aHR 0.34] } \\
\text { CPR duration, min } \\
\quad \text { [aHR 1.02] } \\
\text { SOFA score [aHR 1.35] }\end{array}$ & $\begin{array}{l}\text { Overall 22\% } \\
\text { GPC RTI NA } \\
\text { NFGNB RTI NA }\end{array}$ \\
\hline $\begin{array}{r}\text { Present } \\
\text { study }\end{array}$ & 151 & $51(17-87)$ & $24.5 \%$ & $\begin{array}{l}\text { SOT } 5.3 \% \\
\text { BMT } 9.9 \% \\
\text { Cancer } 17.9 \% \\
\text { Dialysis } 4.6 \%\end{array}$ & $\begin{array}{l}\text { Pneumonia } 50.3 \% \\
\text { Intra-abdominal } 7.9 \% \\
\text { Urinary tract } 0.7 \% \\
\text { Others } 41.4 \% \\
\text { Positive blood } \\
\quad \text { culture } 31.1 \%\end{array}$ & $\begin{array}{l}\text { GPC } 17.2 \% \\
\text { EGNB } 17.9 \% \\
\text { NFGNB } 15.9 \% \\
\text { Fungi } 6.6 \% \\
\text { Unknown } 25.2 \%\end{array}$ & $\begin{array}{l}\text { CPR [aHR 2.74] } \\
\text { Dialysis [aHR 3.62] } \\
\text { Age }>75 \text { y [aHR 1.90] } \\
\text { Admission-to-ECMO, day } \\
\quad \text { aHR 1.22] } \\
\text { Various infection associated } \\
\text { factors }\end{array}$ & $\begin{array}{l}\text { Overall } 30 \% \\
\text { GPC RTI } \\
\mathbf{8 5 . 7} \%(\mathbf{6} / 7)^{*} \\
\text { NFGNB RTI } \\
0 \%(0 / 20)\end{array}$ \\
\hline
\end{tabular}

CPR, Cardiopulmonary resuscitation; SOT, solid organ transplantation; BMT, bone marrow transplantation; GPC, Gram-positive cocci; EGNB, enteric Gram-negative bacilli; $N F G N B$, nonfermentative Gram-negative bacilli; $R T I$, respiratory tract infection; $N A$, not available; $a H R$, adjusted hazards ratio; Trop I, troponin I; SOFA, sequential organ failure assessment score; ECMO, extracorporeal membrane oxygenation. *Virtually identical rates of survival for GPC RTI. 
observed for community-acquired infections than for hospital-acquired infections. ${ }^{16-18}$

Table 5 summarizes previous single-center studies of adults with refractory sepsis undergoing ECMO. In the Korean study, the overall survival-to-discharge was $22 \%$ (7/32), whereas that of the French study was $71 \%$ $(10 / 14)^{7,8}$; however more patients in the former cohort were immunocompromised ( $66 \%$ vs $43 \%$ ) and had cardiac arrests before ECMO (44\% vs $0 \%)$. In addition, more of the Korean cases had positive blood cultures compared with the French study (63\% vs 36\%) and nonrespiratory tract infections (66\% vs14\%); however, consistent with our findings, poor survival rates were documented for the patients with nonfermentative Gram-negative sepsis, in both the Korean cohort $(19 \%, 1 / 6)$ and the French cohort $(33 \%, 1 / 3)$ and with fungal sepsis $(20 \%, 1 / 5)$ in the Korean cohort (no patients had fungal sepsis in the French study). Also in line with our findings, excellent survival was reported by the French study for the patients with Gram-positive bacterial pneumonias $(83 \%, 5 / 6)$ as for our patients $(86 \%, 6 / 7)$.

In both studies, the authors did not associate microbiological factors with outcomes; however, in children, Gram-positive sepsis has been associated with better outcomes since the 1990s. ${ }^{19,20}$ Instead, cardiac dysfunction as opposed to refractory vasoplegia was proposed to predict survival. ${ }^{7,8}$ Profound but reversible cardiac dysfunction is a well-recognized complication of severe sepsis. Septic cardiomyopathy is characterized by ventricular dilatation, reduction in ejection fraction, and reduced contractility. ${ }^{21}$ Because fundamental differences exist in the host response to Gram-positive compared with Gram-negative organisms, we hypothesized that septic cardiomyopathy may be a more prominent feature of Gram-positive sepsis, whereas the paradigm of endotoxin-induced distributive shock with low systemic vascular resistance may be the predominant feature of Gram-negative sepsis. ${ }^{22-24}$ Hence, although we observed decreased left ventricular function to be significantly associated with survival in our univariate analysis, in the multivariate analysis of all septic patients, it was outcompeted by infection characteristics such as Grampositive sepsis or acute myocarditis that dictated the ultimate reversibility of the infection.

The hypothesis that the pathophysiology of sepsis may differ depending on the type of pathogen is supported by experimental models of Staphylococcus aureus, Streptococcus pneumoniae, and endotoxin sepsis, showing initial depressed myocardial function in the former 2 , but relatively preserved cardiac contractility in the latter. ${ }^{24-27}$ Furthermore, a recent paper showing circulating pneumolysin to be a potent inducer of cardiac injury during pneumococcal infection, provides biological plausibility to the assumption that life-threatening acute cardiac complications are more common in pneumococcal infection compared to other bacterial infections. ${ }^{27}$ Of the 14 patients in the exemplary study of Brechot and colleagues, ${ }^{8}$ 6 had pneumococcal pneumonia and 5 survived to discharge. ${ }^{8}$ Among the 7 patients in our study with gram-positive cocci pneumonia, 6 survived to discharge. Even among individual case reports, life-threatening staphylococcal and streptococcal infections with induced septic cardiomyopathy salvaged by VA-ECMO consistently outnumber that of nonfermentative Gram-negative and fungal infections. ${ }^{4,25,28-34}$

Similarly, the better outcomes of ECMO for pediatric septic shock may be explained by the fact that younger children have greater incidences of invasive streptococcal and staphylococcal infections. ${ }^{4,20,35}$ Hence, future studies to discern whether the better outcomes of VA-ECMO used to support septic cardiomyopathy may reflect the underlying differences in microbiology and pathophysiology are warranted.

Even if outcomes correlate well with the type of pathogen, the etiology may not be known at ECMO onset, rendering this less useful as a patient selection criterion. Hence, a cut-off of 4 days from admission as a threshold for initiating ECMO, loosely capturing all communityacquired infections or early sepsis, may be more practical. The crucial impact of ECMO timing for both respiratory and cardiac indications has been suggested previously. ${ }^{15,36}$ For patients with severe ARDS, ECMO initiated beyond a week of mechanical ventilation has been associated with poorer outcomes. ${ }^{36}$ For patients with severe septic shock, shock beyond 30.5 hours before ECMO initiation was associated with $0 \%$ survival. ${ }^{7}$ Because the onset of sepsis or shock is difficult to define precisely, using time from admission or from mechanical ventilation to guide candidate selection is a feasible option that deserves further validation.

Our study was limited by the retrospective and singlecenter design, which meant missing data were inevitable and selection criteria were unusually expansive. ${ }^{13}$ Unlike the largest randomized trial of ECMO in adults for ARDS (the CESAR [Conventional Ventilatory Support Versus Extracorporeal Membrane Oxygenation for Severe Adult Respiratory Failure] trial), patients older than 65 years were not excluded routinely (in fact the oldest survivor in our series was 82 years old), nor were those traditionally considered lacking reversibility. ${ }^{37}$ Hence, we were able to collect such a large cohort with relative few selection biases to study.

Another limitation was the heterogeneity of our study cohort. We did not separate patients with ARDS and catecholamine-managed shock who could be supported with VV-ECMO from catecholamine-refractory septic shock patients who required VA-ECMO for 2 reasons: first, we would in practice treat these patients on a continuous spectrum with VA-ECMO being frequently switched to 
VV-ECMO or vice versa according to the evolving cardiorespiratory parameters, second, statistical analysis of the entire population to identify risk factors is more robust than smaller subgroup analyses (eg, of only VA-ECMO patients) with inherent selection bias. However care may need to be taken in comparing our findings to other studies. For example, an age cut-off of 60 years has been suggested to be a contraindication to ECMO (VA mode) given sepsis, based on the fact that none of the 8 survivors of 52 patients with refractory shock exclusively supported by VA-ECMO were $\geq 60$ years-old. ${ }^{12}$ By studying a larger population, however, including those with better outcomes on VV-ECMO and using a more statistically robust method, ie, (GAMs) of identifying appropriate cut-offs of age, we found that the risk of death after ECMO (any mode) given sepsis increased sharply after 75 years of age and not as early as 60 years. Although this may partially reflect a gap in appropriate age limits between VA and VV modes, we would support a wider berth given that $10(22 \%)$ of our survivors were 60 years or older, including 3 on VA-ECMO (the eldest being 78 years old with refractory shock due to Streptococcus constellatus bacteremia).

We also did not separate viral infections particularly viral myocarditis from bacterial infections because acute myocarditis may be caused by bacteria such as Orientia tsutsugamushi, viruses often coexist with other etiologies, etiologies often were not apparent initially so the distinctions would be artificially made in retrospect, and in any case, the former serves as a useful benchmark as an accepted indication for ECMO for comparison. Furthermore, when we excluded the 30 patients with acute myocarditis from our analysis, the results of the other covariates in the Cox proportional hazards model did not change significantly.

Third, our study spanned over a decade (2001-2011) during which standards of care for patients with sepsis and of ECMO evolved. ${ }^{38}$ However, in a sensitivity analysis of in-hospital mortality rates, we did not find any significant difference in trends over time, in line with a US study of adult ECMO use (2002-2012) that reported stable mortality rates during this time period. ${ }^{39}$ Lastly, we did not find a control group of matched septic patients without ECMO and our conclusions might be more akin to hypothesis generating. Nevertheless, our observations may aid in minimizing poor patient selection for future clinical practice and trials.

\section{CONCLUSIONS}

In conclusion, in this single-center study based on a unique experience of applying ECMO in adults manifesting a wide variety of life-threatening infections, we found that better outcomes were associated with
ECMO applied to patients 75 years or younger, with door-to-ECMO times of 96 hours or less, with Grampositive as opposed to Gram-negative sepsis, and with pneumonia as opposed to primary bloodstream infections. Hence, if ECMO is to be applied to adults with sepsis, clinicians may wish to prioritize younger patients from the community.

\section{Conflict of Interest Statement}

Authors have nothing to disclose with regard to commercial support.

\section{References}

1. Hill JD, O'Brien TG, Murray JJ, Dontigny L, Bramson ML, Osborn JJ, et al. Prolonged extracorporeal oxygenation for acute post-traumatic respiratory failure (shock-lung syndrome). Use of the Bramson membrane lung. $N$ Engl J Med. 1972;286:629-34.

2. Pujara D, Sandoval E, Simpson L, Mallidi HR, Singh SK. The state of the art in extracorporeal membrane oxygenation. Semin Thorac Cardiovasc Surg. 2015; 27:17-23.

3. Skinner SC, Iocono JA, Ballard HO, Turner MD, Ward AN, Davenport DL, et al. Improved survival in venovenous vs venoarterial extracorporeal membrane oxygenation for pediatric noncardiac sepsis patients: a study of the Extracorporeal Life Support Organization registry. J Pediatr Surg. 2012;47:63-7.

4. MacLaren G, Butt W, Best D, Donath S. Central extracorporeal membrane oxygenation for refractory pediatric septic shock. Pediatr Crit Care Med. 2011;12:133-6.

5. Brierley J, Carcillo JA, Choong K, Cornell T, Decaen A, Deymann A, et al Clinical practice parameters for hemodynamic support of pediatric and neonata septic shock: 2007 update from the American College of Critical Care Medicine. Crit Care Med. 2009;37:666-88.

6. Cheng A, Sun HY, Lee CW, Ko WJ, Tsai PR, Chuang YC, et al. Survival of septic adults compared with nonseptic adults receiving extracorporeal membrane oxygenation for cardiopulmonary failure: a propensity-matched analysis J Crit Care. 2013;28:532.e1-10.

7. Park TK, Yang JH, Jeon K, Choi SH, Choi JH, Gwon HC, et al. Extracorporeal membrane oxygenation for refractory septic shock in adults. Eur J Cardiothorac Surg. 2015;47:e68-74.

8. Brechot N, Luyt CE, Schmidt M, Leprince P, Trouillet JL, Leger P, et al Venoarterial extracorporeal membrane oxygenation support for refractory cardiovascular dysfunction during severe bacterial septic shock. Crit Care Med. 2013;41:1616-26.

9. Ko WJ, Chen YS, Chou NK, Wang SS, Chu SH. Extracorporeal membrane oxygenation in the perioperative period of heart transplantation. J Formos Med Assoc. 1997;96:83-90.

10. Huang SC, Wu ET, Wang CC, Chen YS, Chang CI, Chiu IS, et al. Eleven years of experience with extracorporeal cardiopulmonary resuscitation for paediatric patients with in-hospital cardiac arrest. Resuscitation. 2012;83:710-4.

11. Wang CH, Chou NK, Becker LB, Lin JW, Yu HY, Chi NH, et al. Improved outcome of extracorporeal cardiopulmonary resuscitation for out-of-hospital cardiac arrest-a comparison with that for extracorporeal rescue for in-hospital cardiac arrest. Resuscitation. 2014;85:1219-24.

12. Huang CT, Tsai YJ, Tsai PR, Ko WJ. Extracorporeal membrane oxygenation resuscitation in adult patients with refractory septic shock. J Thorac Cardiovasc Surg. 2013;146:1041-6.

13. Ko WJ, Lin CY, Chen RJ, Wang SS, Lin FY, Chen YS. Extracorporeal membrane oxygenation support for adult postcardiotomy cardiogenic shock. Ann Thorac Surg. 2002;73:538-45.

14. Horan TC, Andrus M, Dudeck MA. CDC/NHSN surveillance definition of health care-associated infection and criteria for specific types of infections in the acute care setting. Am J Infect Control. 2008;36:309-32.

15. Schmidt M, Burrell A, Roberts L, Bailey M, Sheldrake J, Rycus PT, et al. Predicting survival after ECMO for refractory cardiogenic shock: the survival after veno-arterial-ECMO (SAVE)-score. Eur Heart J. 2015;36: 2246-56. 
16. Musher DM, Thorner AR. Community-acquired pneumonia. $N$ Engl J Med. 2014;371:1619-28.

17. Torres A, Ferrer M, Badia JR. Treatment guidelines and outcomes of hospitalacquired and ventilator-associated pneumonia. Clin Infect Dis. 2010;51(suppl 1):S48-53.

18. Dabar G, Harmouche C, Salameh P, Jaber BL, Jamaleddine G, Waked M, et al. Community- and healthcare-associated infections in critically ill patients: a multicenter cohort study. Int J Infect Dis. 2015;37:80-5.

19. Stewart DL, Dela Cruz TV, Ziegler C, Goldsmith LJ. The use of extracorporeal membrane oxygenation in patients with gram-negative or viral sepsis. Perfusion. 1997; 12:3-8.

20. Hocker JR, Simpson PM, Rabalais GP, Stewart DL, Cook LN. Extracorporeal membrane oxygenation and early-onset group B streptococcal sepsis. Pediatrics. 1992;89:1-4.

21. Parker MM, Shelhamer JH, Bacharach SL, Green MV, Natanson C, Frederick TM, et al. Profound but reversible myocardial depression in patients with septic shock. Ann Intern Med. 1984;100:483-90.

22. Greisman SE, DuBuy JB, Woodward CL. Experimental gram-negative bacterial sepsis: prevention of mortality not preventable by antibiotics alone. Infect Immun. 1979;25:538-57.

23. Wolff SM. Biological effects of bacterial endotoxins in man. J Infect Dis. 1973; 128(suppl):259-64

24. Opal SM, Cohen J. Clinical gram-positive sepsis: does it fundamentally differ from gram-negative bacterial sepsis? Crit Care Med. 1999;27:1608-16.

25. Soerensen KE, Nielsen OL, Birck MM, Soerensen DB, Leifsson PS, Jensen HE, et al. The use of sequential organ failure assessment parameters in an awake porcine model of severe Staphylococcus aureus sepsis. APMIS. 2012;120: 909-21.

26. Griffin MP, Zwischenberger JB, Minifee PK, Allison PL, Lobe TE. Extracorporeal membrane oxygenation for gram-negative septic shock in the immature pig. Circ Shock. 1991;33:195-9.

27. Alhamdi Y, Neill DR, Abrams ST, Malak HA, Yahya R, Barrett-Jolley R, et al. Circulating pneumolysin is a potent inducer of cardiac injury during pneumococcal infection. PLoS Pathog. 2015;11:e1004836.

28. Vohra HA, Adamson L, Weeden DF, Haw MP. Use of extracorporeal membrane oxygenation in the management of septic shock with severe cardiac dysfunction after Ravitch procedure. Ann Thorac Surg. 2009;87:e4-5.

29. Porizka M, Kopecky P, Prskavec T, Kunstyr J, Rulisek J, Balik M. Successful use of extra-corporeal membrane oxygenation in a patient with streptococcal sepsis: a case report and review of literature. Prague Med Rep. 2015;116:57-63.
30. Firstenberg MS, Abel E, Blais D, Louis LB, Steinberg S, Sai-Sudhakar C, et al. The use of extracorporeal membrane oxygenation in severe necrotizing soft tissue infections complicated by septic shock. Am Surg. 2010; 76:1287-9.

31. De Rosa FG, Fanelli V, Corcione S, Urbino R, Bonetto C, Ricci D, et al. Extra Corporeal Membrane Oxygenation (ECMO) in three HIV-positive patients with acute respiratory distress syndrome. BMC Anesthesiol. 2014; $14: 37$.

32. Cawcutt K, Gallo De Moraes A, Lee SJ, Park JG, Schears GJ, Nemergut ME. The use of ECMO in HIV/AIDS with Pneumocystis jirovecii pneumonia: a case report and review of the literature. ASAIO J. 2014;60:606-8.

33. Hagiwara S, Murata M, Aoki M, Kaneko M, Oshima K. Septic shock caused by Klebsiella oxytoca: an autopsy case and a survival case with driving extracorporeal membrane oxygenation. Hippokratia. 2013;17:171-3.

34. Fujisaki N, Takahashi A, Arima T, Mizushima T, Ikeda K, Kakuchi H, et al. Successful treatment of Panton-Valentine leukocidin-expressing Staphylococcus aureus-associated pneumonia co-infected with influenza using extracorporeal membrane oxygenation. In Vivo. 2014;28:961-5.

35. Maclaren G, Butt W, Best D, Donath S, Taylor A. Extracorporeal membrane oxygenation for refractory septic shock in children: one institution's experience. Pediatr Crit Care Med. 2007;8:447-51.

36. Schmidt M, Zogheib E, Roze H, Repesse X, Lebreton G, Luyt CE, et al. The PRESERVE mortality risk score and analysis of long-term outcomes after extracorporeal membrane oxygenation for severe acute respiratory distress syndrome. Intensive Care Med. 2013;39:1704-13.

37. Peek GJ, Mugford M, Tiruvoipati R, Wilson A, Allen E, Thalanany MM, et al. Efficacy and economic assessment of conventional ventilatory support versus extracorporeal membrane oxygenation for severe adult respiratory failure (CESAR): a multicentre randomised controlled trial. Lancet. 2009;374: 1351-63.

38. Maxwell BG, Powers AJ, Sheikh AY, Lee PH, Lobato RL, Wong JK. Resource use trends in extracorporeal membrane oxygenation in adults: an analysis of the Nationwide Inpatient Sample 1998-2009. J Thorac Cardiovasc Surg. 2014; 148:416-21, e1.

39. McCarthy FH, McDermott KM, Kini V, Gutsche JT, Wald JW, Xie D, et al. Trends in U.S. extracorporeal membrane oxygenation use and outcomes: 2002-2012. Semin Thorac Cardiovasc Surg. 2015;27:81-8.

Key Words: extracorporeal life support, sepsis, infections, shock, ARDS, early rescue, community-acquired pneumonia 


\section{APPENDIX E1 \\ Technical Information Regarding the Venoarterial Extracorporeal Membrane Oxygenation (ECMO) Circuit}

The ECMO system consisted of a centrifugal blood pump (Bio-Pump BP-80; Medtronic, Minneapolis, Minn), a hollow-fiber membrane oxygenator (Affinity; Omnis AOT GmbH, Bad Oyenhausen, Germany) with an integral heat exchanger, and 2 thin-walled cannulae (Medtronic Inc, Anaheim, Calif), all of which were coated with a heparin-bonded Carmeda BioActive Surface (Carmeda AB, Upplands Väsby, Sweden). For simplicity the ECMO circuit was primed only with normal saline containing heparin at a concentration of $2 \mathrm{U} / \mathrm{mL}$. An additional 5000 $\mathrm{U}$ of heparin were injected intravenously during cannulation. Heparin was not again used in the first 24 hours of ECMO support.

After 24 hours of ECMO support, heparin infusion was started to keep the activated clotting time in the range of 160 to 180 seconds, depending on clinical judgment for the risk of bleeding. The dilution anemia occurring after the patient was connected to the ECMO was corrected by packed red blood cell transfusion. The hematocrit was maintained at $30 \%$ to $35 \%$. Although lower hematocrit reduced blood oxygen-carrying capacity, a greater hematocrit increased the risk of clot formation in the ECMO. Platelets were transfused when the platelet count was less than $50 \times 10^{3} / \mathrm{mm}^{3}$, unless a bleeding complication was present.

The femoral route was preferred to the open sternotomy route for ECMO support because the presence of an open sternotomy wound increased the risk of bleeding and infection, and made nursing care more difficult. The centrifugal pump was typically set at a speed of $224 \mathrm{G}$. The blood flow would be more than $2 \mathrm{~L} / \mathrm{min}$.

Adequacy of arterial oxygen saturation was measured by a pulse oximeter and the MX-2 tri-optic measurement cell (Medtronic), the latter was attached to the pre- and postoxygenator circuit to continuously monitor blood oxygen saturation and hematocrit. Continuous monitoring by the pulse oximeter and the MX-2 monitor made frequent blood gas examinations unnecessary; therefore, blood gas was checked once a day. Hematology and blood biochemistry were checked once a day and when clinically indicated. Adequacy of circulatory support was measured by the arterial pulse pressure, which in addition to daily bedside echocardiography, monitored the function of the left heart and was used as a guide to taper inotropic agents infusion. A flattened arterial pressure wave indicated left heart drainage.
Sedation by infusion of midazolam and fentanyl was used routinely. Diuretics maintained fluid balance. A hemofilter (FH66; Gambro, Hechingen, Germany) was connected between the ECMO arterial and venous circuits for hemofiltration, if dialysis was required. Neither microporous membrane oxygenator nor centrifugal pump was intended for prolonged use. The indications of ECMO replacement included severe plasma leakage from the oxygenator, deterioration of the oxygenator gas exchange function, decreased ECMO blood flow, or hemoglobinuria. A policy of replacing the entire ECMO circuits rather than the centrifugal pump or the oxygenator alone was followed for safety and simplicity.

\section{Definitions of the Main Types of Infection}

All infections were defined in the context of symptoms and signs of infection. Laboratory-confirmed primary bloodstream infections were defined by the presence of a recognized pathogen cultured from one or more blood cultures or of a common skin contaminant (eg, coagulase negative staphylococci) from 2 or more blood cultures from 2 separate occasions not related to an infection at another site.

Acute myocarditis was defined by either culture of organisms from pericardial tissue or by at least 2 of the following with no other recognized cause: fever, chest pain, paradoxical pulse, or increased heart size AND at least 1 of the following: abnormal ECG consistent with myocarditis, evidence of myocarditis on endomyocardial biopsy, pericardial effusion, positive blood viral antigen test or DNA.

Pneumonia was defined by radiologic findings not solely attributable to other causes, symptoms and signs of fever, abnormal white blood cell count $\left(<4000 / \mathrm{mm}^{3}\right.$ or $\left.>12,000 / \mathrm{mm}^{3}\right)$, or altered mental status without other known cause in $\geq 70$-year-old patient AND at least 2 of the following respiratory tract presentations (new onset or increase in sputum amount and purulence, cough/dyspnoea, new auscultation findings, worsening gas exchange) WITH or WITHOUT relevant laboratory findings such as positive blood culture not related to infection elsewhere or matching sputum (eg pneumococcus), positive pleural fluid culture, positive quantitative culture from minimally contaminated lower respiratory tract specimens (eg, bronchoalveolar lavage or protected brush specimen), lung or pleura histopathology (eg, for cytomegalovirus), positive paired sera with 4-fold IgG rise (eg, for Mycoplasma), positive detection of viral antigen or DNA from respiratory secretions (eg, influenza),or urine antigen testing (eg, pneumococcus, Legionella pneumophilia). 